\title{
Comparison of A-mode and B-mode Ultrasound for Measurement of Subcutaneous Fat
}

\section{Dale R. Wagner*,}

dale.wagner@usu.edu

Masaru Teramoto

Trenton Jud

Joshua Gordon*

Casey McPherson*

Adrianna

${ }^{*}$ Kinesiology \& Health Science Department, Utah State University, Logan, UT, USA

${ }^{\dagger}$ Division of Physical Medicine \& Rehabilitation, University of Utah, Salt Lake City, UT, USA

${ }^{\mathbf{1}}$ Address correspondence to: Dale R. Wagner, Ph.D., 7000 Old Main Hill, Utah State University, Logan, UT 84322-7000.

\section{Abstract}

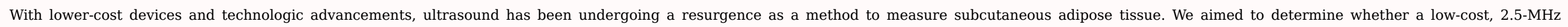

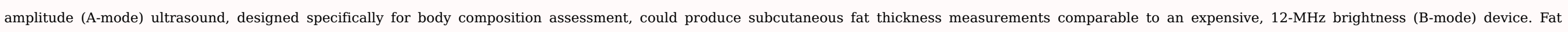

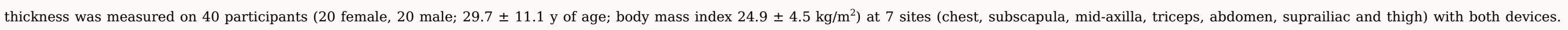

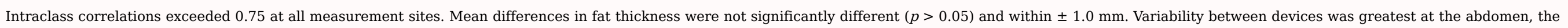
site with the greatest thickness. The low-cost, low-resolution A-mode ultrasound provides subcutaneous fat thickness measurements similar to the more expensive, high-resolution B-mode ultrasound.

Key Words: Amplitude modulation; Body composition; Body fat; Fat thickness; Subcutaneous adipose tissue; Validity

\section{Introduction}

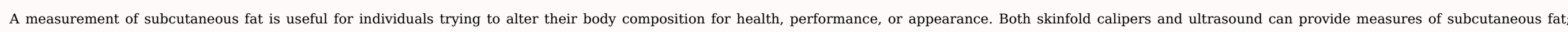

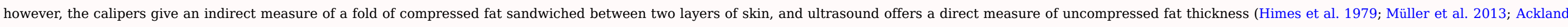

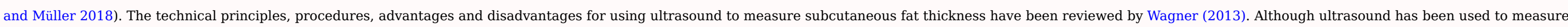

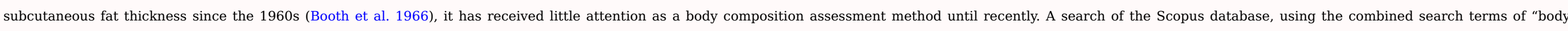

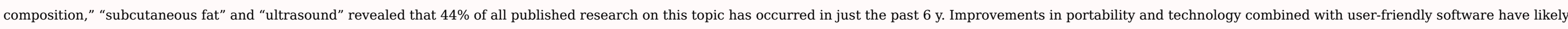
fueled this resurgence in the interest of ultrasound as a body composition assessment method.

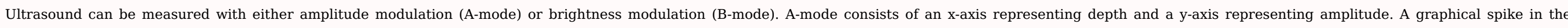

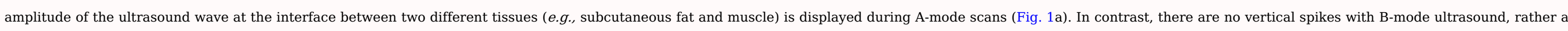

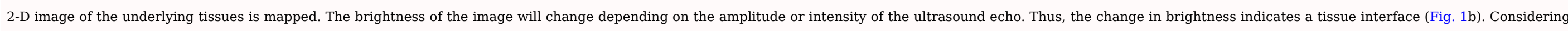

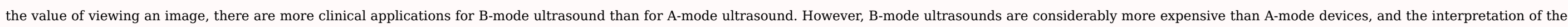



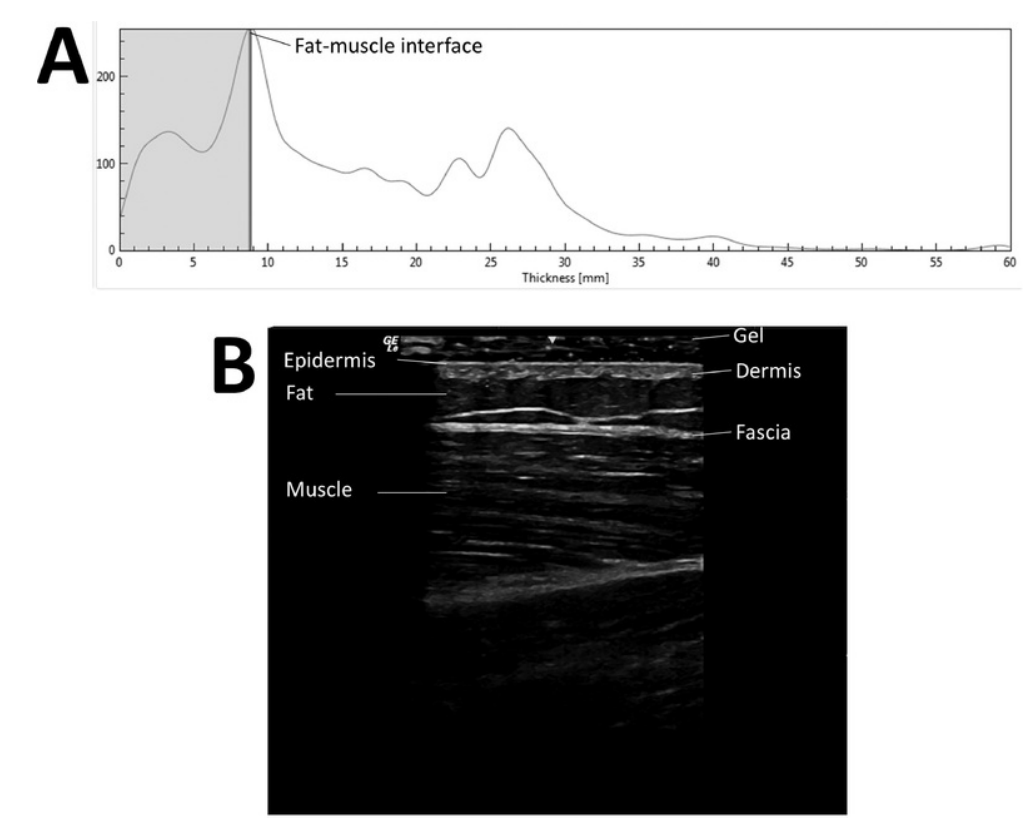

Fig. 1 Images of ultrasound scans from (a) A-mode and (b) B-mode.

\section{alt-text: Fig 1}

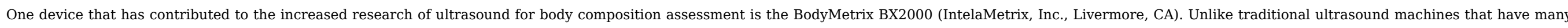

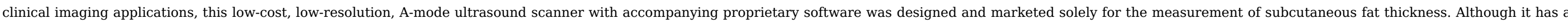

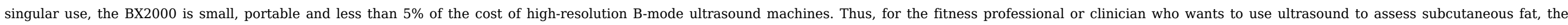
BodyMetrix BX2000 is an appealing option if it proves to be valid.

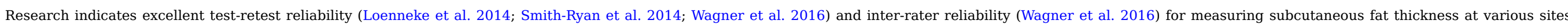

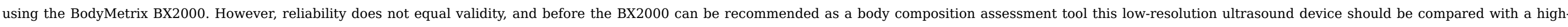

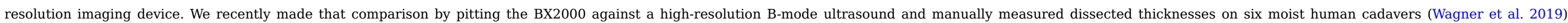

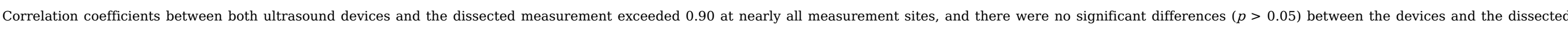

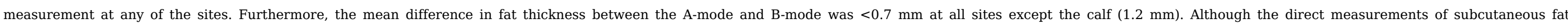

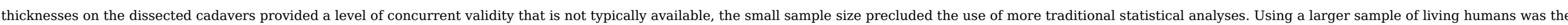

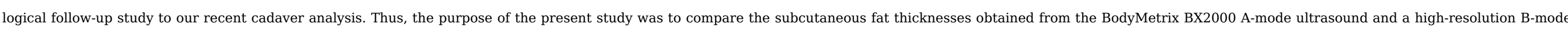
ultrasound.

\section{Materials and Methods \\ Participants}

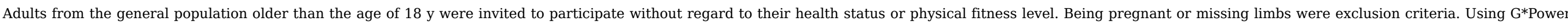

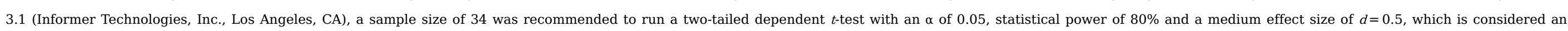




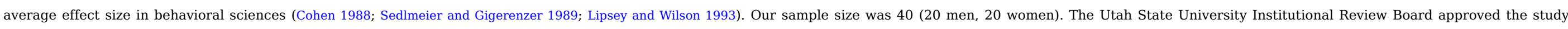
(protocol \#8249), and participants signed a written informed consent before any data collection.

\section{Procedures}

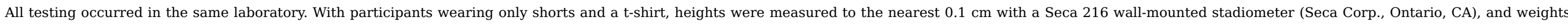
were measured to the nearest $0.1 \mathrm{~kg}$ with a Seca 869 digital scale. Each individual's height, weight and both A-mode and B-mode ultrasound measurements were completed in a single session.

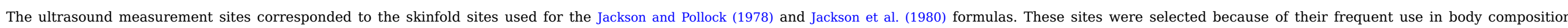

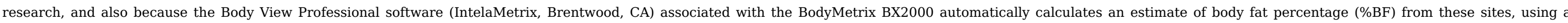
proprietary formula. This \%BF estimate was valuable to the participants and served as a recruitment tool for participation

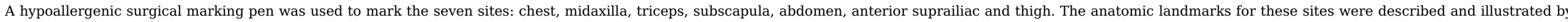

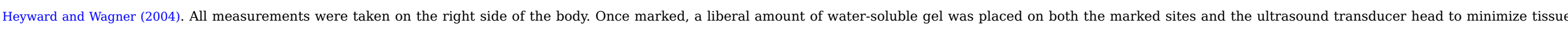
compression. The transducer head was essentially hydroplaning across the skin. Gel was wiped off and reapplied when switching from one device to the other.

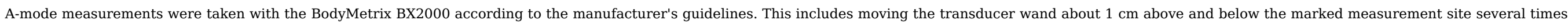

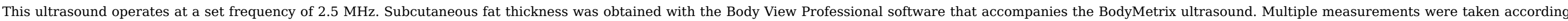
to the software prompts.

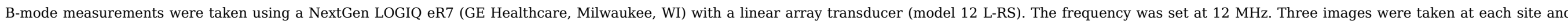

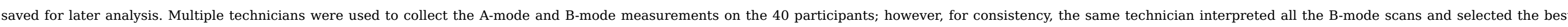

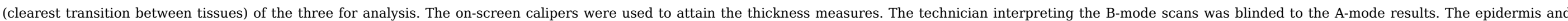
dermis were included in the thickness comparison of both ultrasounds.

\section{Statistical analyses}

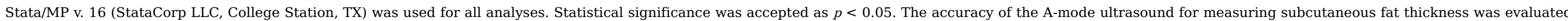
against the B-mode ultrasound measurements. The following statistical tests and evaluative criteria were used to make a decision regarding the validity of the A-mode device:

- Equivalence tests of means with $1 \mathrm{~mm}$ difference as delta reveal no significant mean difference between the A-mode and B-mode measurements (Schuirmann 1987; Goldstein 1994; Walker and Nowacki 2011),

- Intra-class correlations (ICCs) are excellent (ICC $\geq 0.75$ ) between the two devices (Shrout and Fleiss 1979; Cicchetti 1994; McGraw and Wong 1996), and

- Bland and Altman (1999) plots of residual scores (average of A-mode and B-mode plotted against each participant's error score) are random with nonsignificant correlation, indicating no systematic bias.

\section{Results}

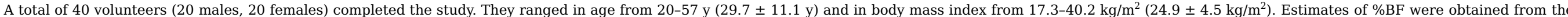
BX2000's proprietary conversion of the Jackson and Pollock (1978) and Jackson et al. (1980) formulas for men and women, respectively. The \%BF for the sample ranged from 6.4\%-32.4\% (19.4 $\pm 6.6 \%$ ).

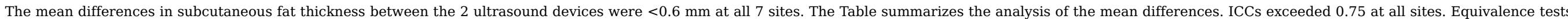

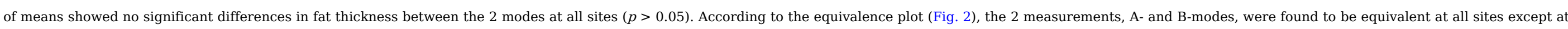

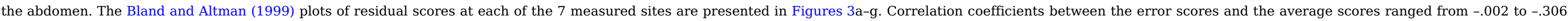

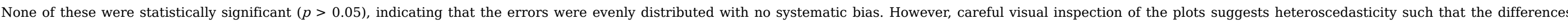

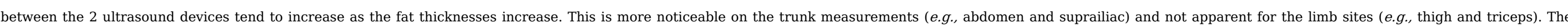

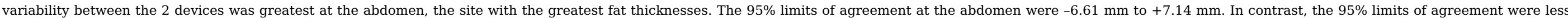


than $\pm 4 \mathrm{~mm}$ at all other measurement sites

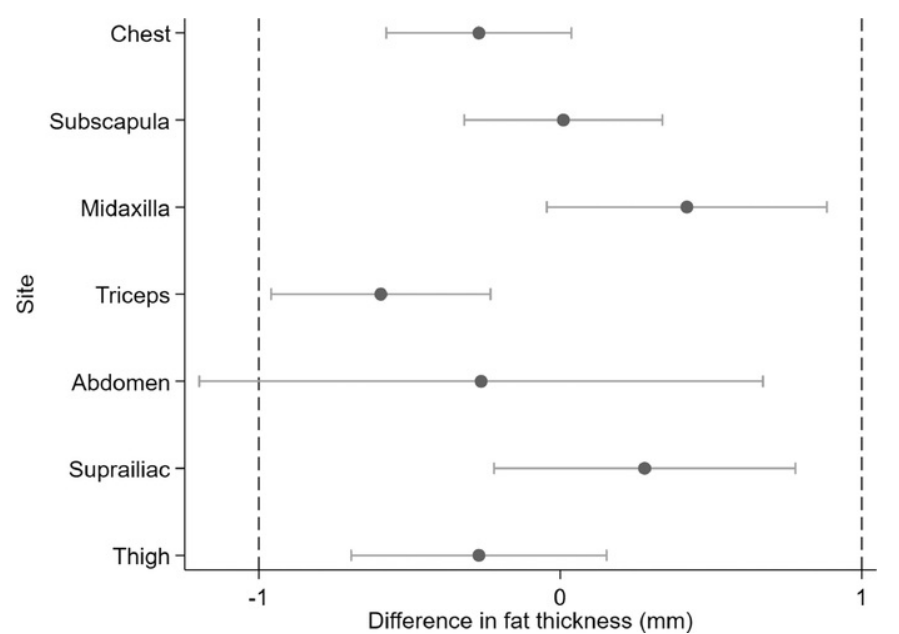

Fig. 2 Plot for equivalence tests of means for fat thickness measured with A-mode minus B-mode ultrasound devices. alt-text: Fig 2 

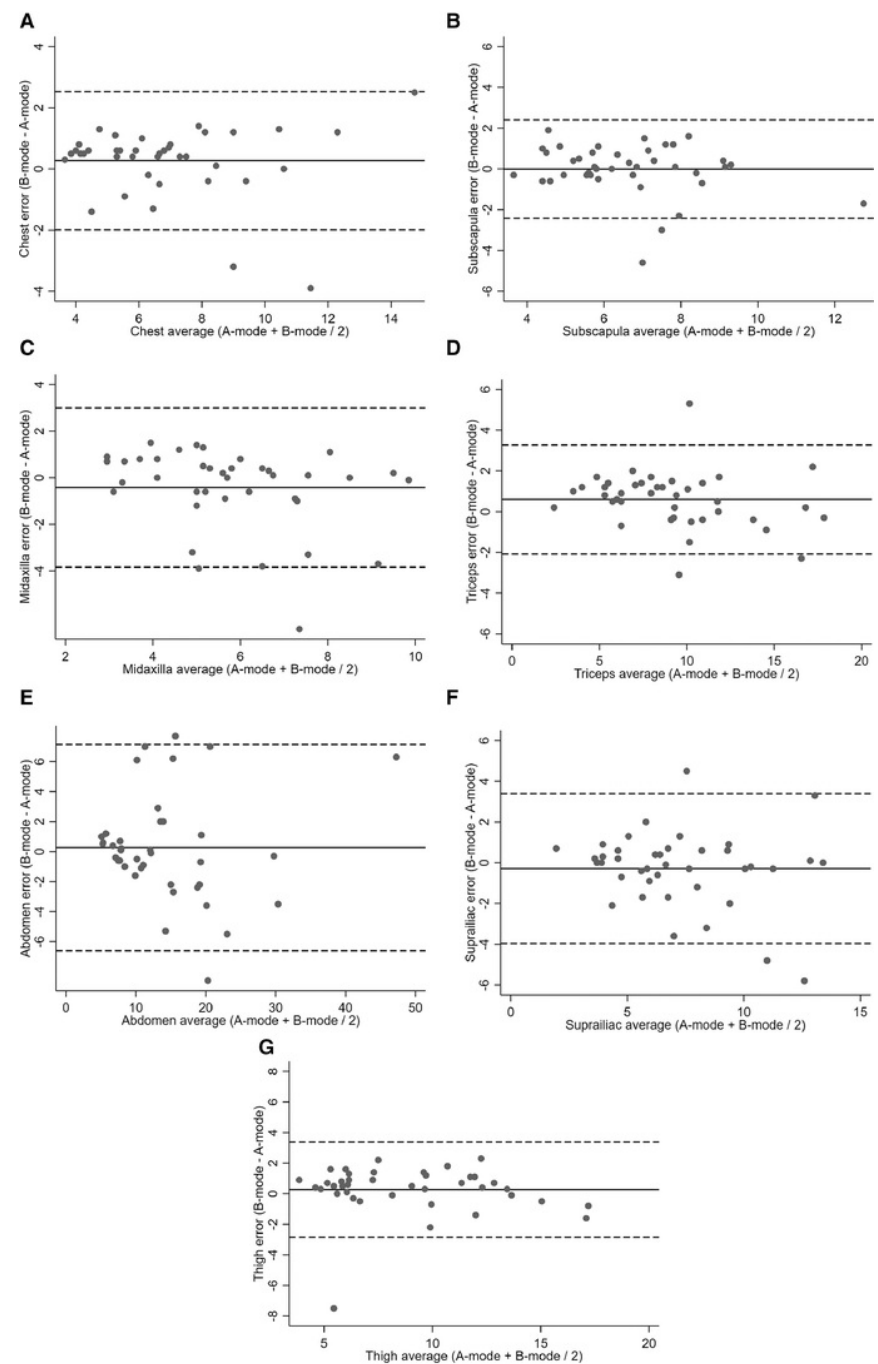

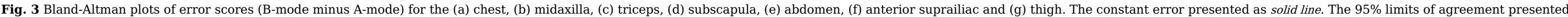
as dotted lines. All values are presented in millimeters.

\section{Discussion}

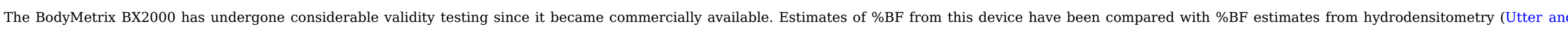

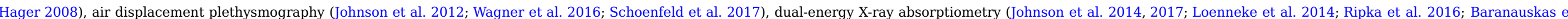

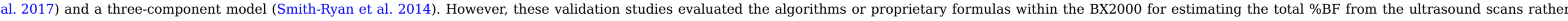

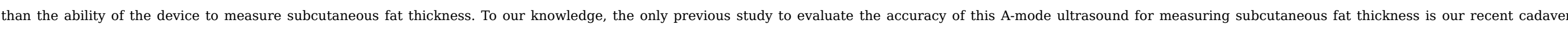
analysis (Wagner et al. 2019). 


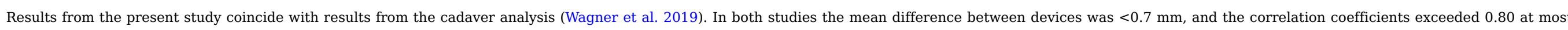

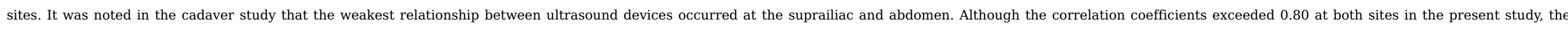

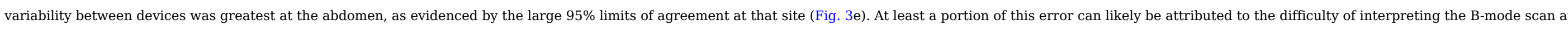

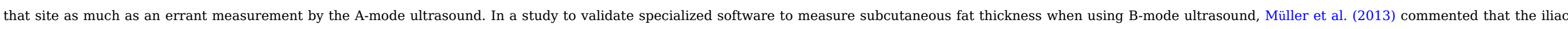

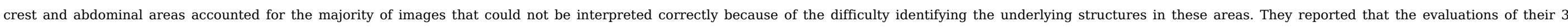

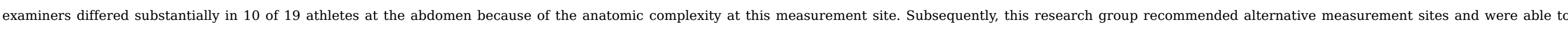

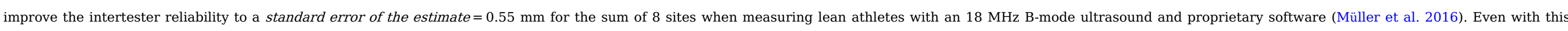

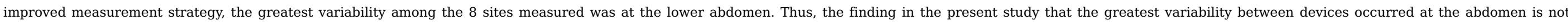
surprising.

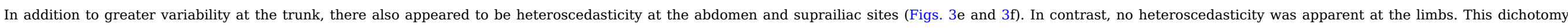

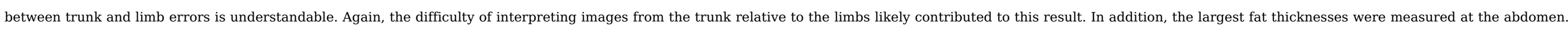
Thus, it is logical that the site producing the largest values would be at most risk for a heteroscedasticity error.

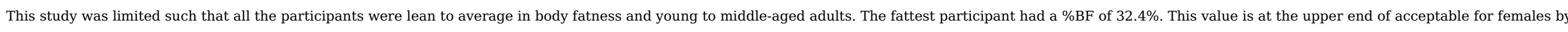

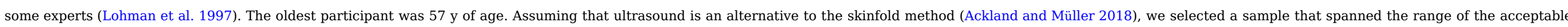

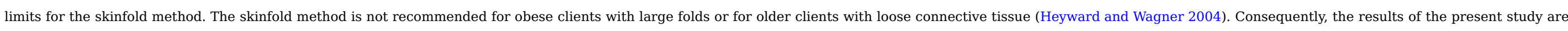

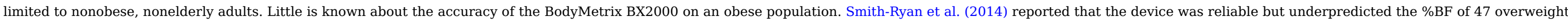

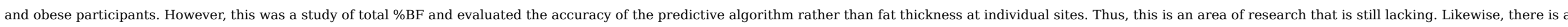
dearth of research regarding the validity of the ultrasound method on an older population.

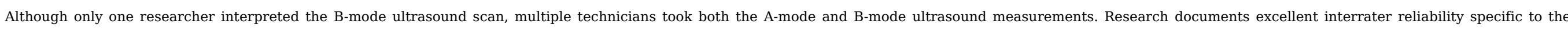

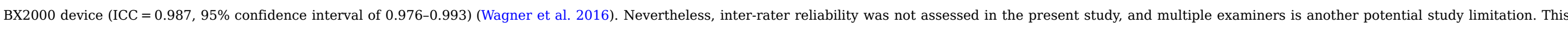

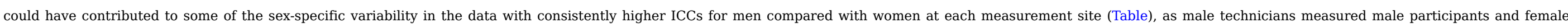
technicians measured female participants. Whether the ultrasound method, and more specifically the BX2000, has greater validity in males than in females requires more research.

Table Comparison of A-mode and B-mode ultrasound subcutaneous fat thicknesses at 7 sites

\begin{tabular}{|l|l|l|}
\hline \multicolumn{2}{|c|}{ Site } & \multicolumn{2}{c|}{ Mean difference* $(\mathrm{mm})$} & $\mathbf{. 9 4 7}$ \\
\hline Chest & $\mathbf{- 0 . 2 7}$ & .987 \\
\hline Male & -0.71 & .896 \\
\hline Female & 0.17 & $\mathbf{. 8 7 9}$ \\
\hline Subscapula & $\mathbf{0 . 0 1}$ & $\mathbf{. 9 4 6}$ \\
\hline Male & -0.47 & $\mathbf{. 8 1 7}$ \\
\hline Female & 0.49 & $\mathbf{. 7 6 3}$ \\
\hline Midaxilla & $\mathbf{0 . 4 2}$ & .968 \\
\hline Male & -0.28 & .968 \\
\hline Female & 1.12 & $\mathbf{. 6 1 8}$ \\
\hline Triceps & $\mathbf{- 0 . 5 9}$ & $\mathbf{. 9 6 8}$ \\
\hline
\end{tabular}




\begin{tabular}{|l|l|l|}
\hline Male & -0.96 & .987 \\
\hline Female & -0.23 & .947 \\
\hline Abdomen & $\mathbf{- 0 . 2 6}$ & $\mathbf{. 9 5 6}$ \\
\hline Male & -1.36 & .977 \\
\hline Female & 0.83 & .894 \\
\hline Suprailiac & $\mathbf{0 . 2 8}$ & $\mathbf{. 8 9 6}$ \\
\hline Male & -0.20 & .954 \\
\hline Female & 0.76 & .844 \\
\hline Thigh & $\mathbf{- 0 . 2 7}$ & $\mathbf{. 9 5 0}$ \\
\hline Male & -0.62 & .980 \\
\hline Female & 0.08 & .901 \\
\hline
\end{tabular}

* A-mode minus B-mode.

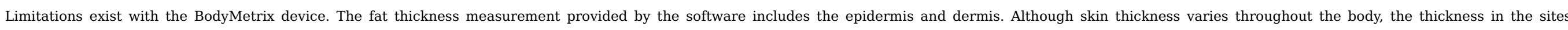

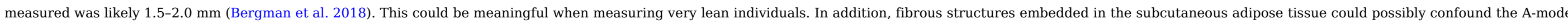

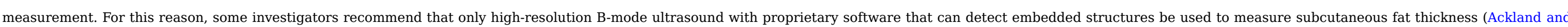

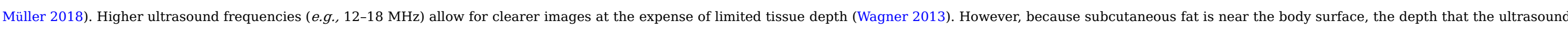
signal can penetrate is of less importance, particularly when measuring the subcutaneous fat of lean individuals.

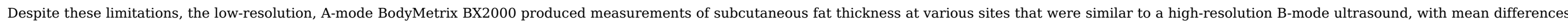

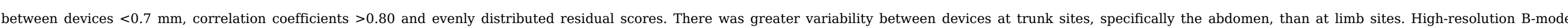

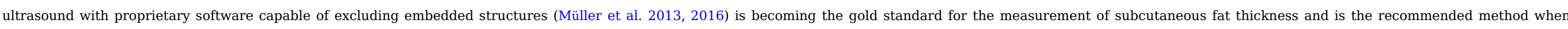

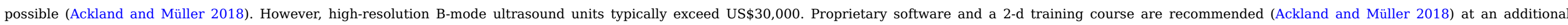

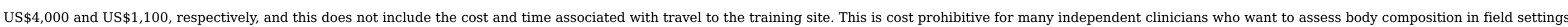

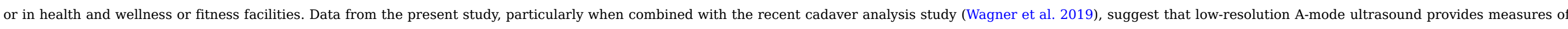
subcutaneous fat thickness that are similar to high-resolution B-mode results. This might be an acceptable and feasible alternative to those who do not have access to the more costly B-mode devices.

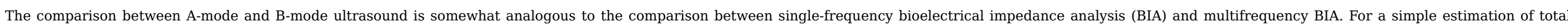

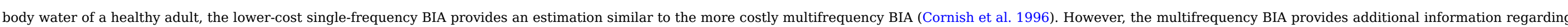

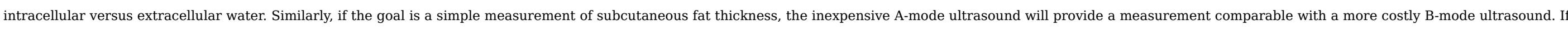
it is important to identify the thickness of the dermis or embedded structures within the subcutaneous fat layer, then a B-mode ultrasound is needed.

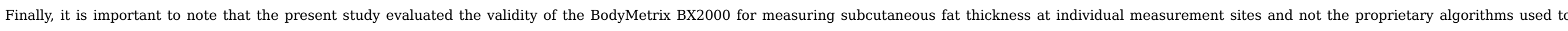

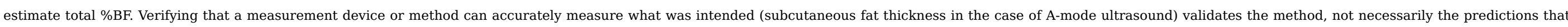

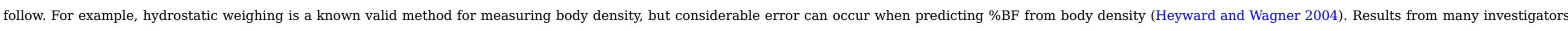

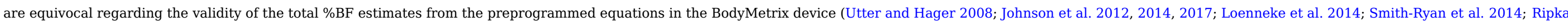

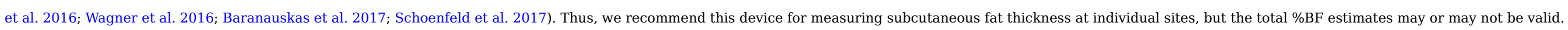

\section{Acknowledgments}


Thanks to Dr. Brennan Thompson for his expert consultation with B-mode ultrasound measurements.

\section{Conflict of Interest disclosure}

The authors have no conflict of interest to disclose.

\section{References}

Ackland T.R. and Müller W., Imaging method: Ultrasound, In: Hume P.A., Kerr D.A. and Ackland T.R., (Eds.), Best practice protocols for physique assessment in sport, 2018, Springer; Singapore, 131-141.

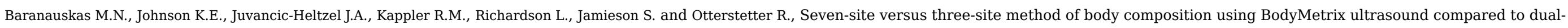
energy X-ray absorptiometry, Clin Physiol Funct Imaging 37, 2017, 317-321.

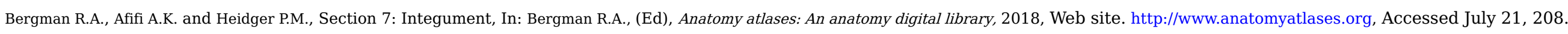

Bland J.M. and Altman D.G., Measuring agreement in method comparison studies, Stat Methods Med Res 8, 1999, 135-160.

Booth R.A.D., Goddard B.A. and Paton A., Measurement of fat thickness in man: A comparison of ultrasound, Harpenden calipers and electrical conductivity, BrJ Nutr 20, 1966, 719-725.

Cicchetti D.V., Guidelines, criteria, and rules of thumb for evaluating normed and standardized assessment instruments in psychology, Psychol Assess 6, 1994, 284-290.

Cohen J., Statistical power analysis for the behavioral sciences, 1988, Lawrence Erlbaum Associates; Mahwah, NJ.

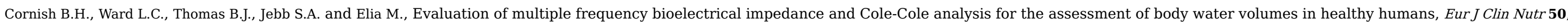
1996, 159-164.

Goldstein R., SG21: Equivalency testing, Strata Tech Bull STB-17, 1994, 13-18.

Heyward V.H. and Wagner D.R., Applied body composition assessment, 2nd ed., 2004, Human Kinetics; Champaign, IL.

Himes J.H., Roche A.F. and Siervogel R.M., Compressibility of skinfolds and the measurement of subcutaneous fat, Am J Clin Nutr 32, 1979, 1734-1740.

Jackson A.S. and Pollock M.L., Generalized equations for predicting body density of men, BrJ Nutr 40, 1978, 487-504.

Jackson A.S., Pollock M.L. and Ward A., Generalized equations for predicting body density of women, Med Sci Sports Exerc 12, 1980, 175-182.

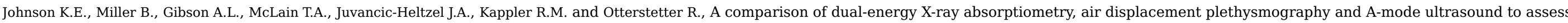
body composition in college-age adults, Clin Physiol Funct Imaging 37, 2017, 646-654.

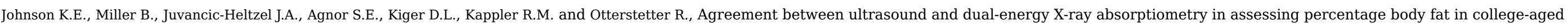
adults, Clin Physiol Funct Imaging 34, 2014, 493-496.

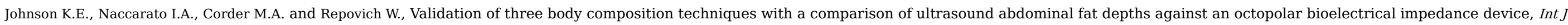
Exerc SCi 5, 2012, 205-213.

Lipsey M.W. and Wilson D.B., The efficacy of psychological, educational, and behavioral treatment: Confirmation from meta-analysis, Am Psychol 48, 1993, 1181-1209.

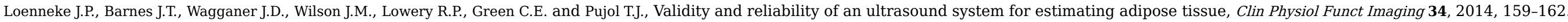

Lohman T.G., Houtkooper L. and Going S.B., Body fat measurement goes high-tech: Not all are created equal, ACSMs Health Fit J 1, 1997, 30-35.

McGraw K.O. and Wong S.P., Forming inferences about some intraclass correlation coefficients, Psychol Methods 1, 1996, 30-46. 


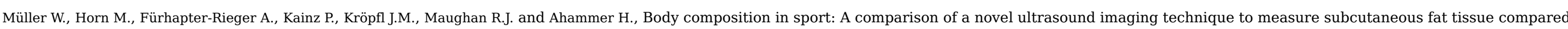
with skinfold measurement, BrJ Sports Med 47, 2013, 1028-1035.

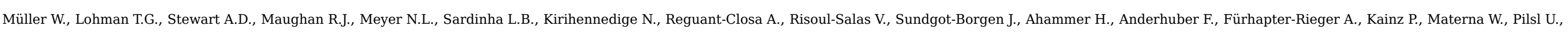

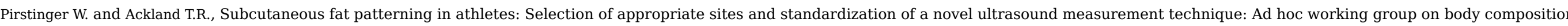
health and performance, under auspices of the IOC Medical Commission, BrJ Sports Med 50, 2016, 45-54.

Ripka W.L., Ulbricht L., Menghin L. and Gewehr P.M., Portable A-mode ultrasound for body composition assessment in adolescents, J Ultrasound Med 35, 2016, 755-760

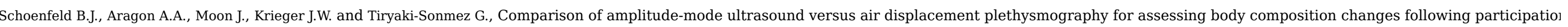
in a structured weight-loss programme in women, Clin Physiol Funct Imaging 37, 2017, 663-668.

Schuirmann D.J., A comparison of the two one-sided tests procedure and the power approach for assessing the equivalence of average bioavailability, J Pharmacokinet Biopharm 15, 1987, 657-680.

Sedlmeier P. and Gigerenzer G., Do studies of statistical power have an effect on the power of studies?, Psychol Bull 105, 1989, 309-316.

Shrout P.E. and Fleiss J.L., Intraclass correlations: Uses in assessing rater reliability, Psychol Bull 86, 1979, 420-428.

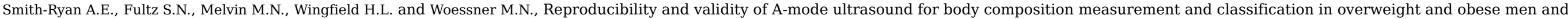
women, PLoS One 9, 2014, e0091750.

Utter A.C. and Hager M.E., Evaluation of ultrasound in assessing body composition of high school wrestlers, Med Sci Sports Exerc 40, 2008, 943-949.

Wagner D.R., Ultrasound as a tool to assess body fat, J Obes 2013, 280713.

Wagner D.R., Cain D.L. and Clark N.M., Validity and reliability of A-mode ultrasound for body composition assessment of NCAA division I athletes, PLoS One 2016, e0153146.

Wagner D.R., Thompson B.J., Anderson D.A. and Schwartz S., A-mode and B-mode ultrasound measurement of fat thickness: A cadaver validation study, EurJ Clin Nutr 73, 2019, 518-523.

Walker E. and Nowacki A.S., Understanding equivalence and noninferiority testing, J Gen Intern Med 26, 2011, 192-196.

\section{Queries and Answers}

Query: Please confirm that givennames and surnames have been identified correctly.

Answer: Yes

Query: Please indicate the significance of the bold values in the table.

Answer: Bold values are for the total sample (male and female combined)

Query: The author names have been tagged as given names and surnames (surnames are highlighted in teal color). Please confirm if they have been identified correctly.

Answer: These are correct. 